\title{
ADAPTATION OF A BOUSSINESQ WAVE MODEL FOR DUNE EROSION MODELING
}

\author{
Nils Drønen ${ }^{1}$ and Rolf Deigaard ${ }^{1}$
}

\begin{abstract}
In the present paper we consider the adaptation of the Boussinesq wave model MIKE21 BW to the case of dune erosion. The process of dune front erosion and redistribution of the eroded dune material was described by two separate models. Erosion was modeled as an effect of direct impact from wave fronts on the dune front and subsequently slumping. Redistribution of the slumped material was modeled using a simple power law model connecting the depth integrated flow velocity with the local sediment transport. The paper presents three model tests. First the model was tested against Deltaflume experiment T01 showing a good overall agreement. Then the model was run for a number of numerical test cases: 1) Sensitivity to main parameters and 2) the effect of adding sand to the dune foot as a mean to protect the erosion
\end{abstract}

Keywords: Dune erosion; morphological modeling; Boussinesq

\section{INTRODUCTION}

Coastal regions are facing an increasing number of challenges: Erosion, overflows and breaching of sea defense are expected to become more and more frequent scenarios in the future as extreme weather incidences are expected to increase in both numbers and strength. Adding the long term trends of rise in sea level - potentially exposing higher points of the coast and increasing the risk of inundation of low lying areas - the pressure on the coast is increasing significantly and the coastal societies are forced to develop and implement realistic solutions to mitigate the negative effects. In order to properly estimate the potential effect of different mitigation measures and strategies, the role of numerical modeling of coastal processes is expected to become increasingly important.

The state-of-the-art model tools used for analyzing coastal process problems today incorporate many useful aspects of the coast zone's physical processes, e.g. spectral wave and storm surge models for analyzing extreme events and occurrence, and coastal flow models coupled with sediment transport and morphology to increase to the understanding of the problem of erosion in a number of important cases. But as the demand for more accurate predictions increases, dedicated engineering models for the specific problems are needed.

The case of dunes and dune erosion is very important in the context described above, because dunes often play a key role as a defense against flooding of the hinterland. Many examples can be given where erosion and breaching of dune systems has caused local damage and flooding.

Over the decades both the qualitative behaviour and order of magnitude estimates of dune erosion have been collected, analyzed and reported. Large scale laboratory experiments as well as field studies have helped increase the knowledge on dunes and dune erosion significantly (Fisher et al. (1986), Overton et al. (1987), Nishi and Kraus (1996), van Gent (2008), Dette et al. (2002), and others), but it is only recently that this knowledge is starting to be incorporated in models.

Over the last number of years models for flows over sea defences, dike or dunes, have started to emerge. In the case of overtopping the models range from simple empirical formulas to flow models based in shallow water equations (Hubbard and Dodd (2002), Kobayashi et al. (2010), Tuan and Oumeraci (2010)) over phase resolving models e.g. based on Boussinesq equations (Lynnet et al. (2010), Fuhrman and Madsen (2008), Drønen and Deigaard (2011)), to attempts to adopt more detailed CFD modeling approaches. Some of these models also include sediment transport and morphological evolution (e.g. Roelvink et al. (2009), Drønen and Deigaard (2011)).

In the case of models dedicated to the process of dune erosion, the number of available models is still relatively limited. An analytical model has been developed by Larson et al. (2004) based on empirical knowledge about dune front erosion and a simple model for the impact of waves on the dune. An important contribution to the development of numerical 2DH models is the so-called XBeach model (Roelvink et al. (2009)), based on a separation of the wave field in long and short waves, modeling the long waves in a phase resolving domain and the short waves in a phase averaged domain. In that model, dune erosion is implicitly represented through a concept where a maximum slope is to be given by the user.

The present work adds to this line of development by presenting a new model based on a phase resolving depth integrated approach for the flow.

\footnotetext{
${ }^{1}$ Coastal and Estuarine Department (CED), DHI, Agern Alle 5, Hoersholm, 2970, Denmark
} 


\section{INTRA WAVE MODELLING INCLUDING DUNE EROSION AND SEDIMENT TRANSPORT}

Dune erosion is a phenomenon that is a result of a number of different flow, sediment mobilization and redistribution processes.

As the sediment mobilization is a function of flow forces acting on the sediment, the modeling of the flow is of utmost importance. Many different hydrodynamic mechanisms have to be described in the case of dune erosion. First there is the basic transformation of waves from deeper areas to the shore during high storm surge water levels. Then there are a number of complex wave phenomena in the surf zone interacting with the waves reflected from the dune front: Waves break close to shore, long bound waves are released and waves reflect from the steep dune front and interact with the waves propagating towards shore. At the dune the effect of wave run-up, wave slamming and down-rush is of utmost importance for how the wave impacts the dune. In principle these processes could be modeled by a very detailed CFD model. For practical engineering models it is however necessary to introduce simplified and parameterized descriptions for parts of the problem. The level of approximation is guided by the need for accuracy and detail on one hand and CPU resources available compared to the number of runs needed and size of domain on the other hand. Based on this discussion it was found interesting to adopt a Boussinesq wave model with wave breaking to describe the flow scenario sketched above.

The erosion and sediment processes relating to these different flows are very complex and it must be expected that parts of the problem cannot be described by deterministic models.

In summary, the purpose of the present study was defined as to test the applicability of a model adapting a Boussinesq wave model to the process of dune erosion. In the following sections a brief model description is given before results are presented and discussed.

\section{DH Boussinesq model}

The Boussinesq wave model MIKE21 BW was adopted to include the effect of dune erosion and sediment transport over a morphologically evolving bed. The flow equations and the solution technique in the MIKE21 BW model are described in Madsen et al. (1997). The model has been a working horse at DHI for many years e.g. for modeling wave disturbance in and around harbours, but its use in the coastal zone has been more limited, partly due to limits in CPU resources in the past. This factor has changed and the model is now being tested for different applications in the coastal zone. In this context different changes to the original model has been made to improve the models ability to capture high Froude number flows and wet-dry boundary, and also improve the modeling of wave breaking in the surf zone. To produce waves, the model includes an internal wave generator that is fed by a time series generated by a specialized tool for random wave generation (see the MIKE21 reference manual).

One interesting feature of the model is that it can be applied as a 2DH area model and may hence in principle be able to cover complex undulating bathymetries. In the present paper however, we present only results from the $1 \mathrm{DH}$ case focusing on the evolution of the profile for an eroding sandy dune.

The model is presented and discussed in Drønen and Deigaard (2011) for the case of wave overtopping and backside erosion of a sandy barrier, but for the case of completeness, one of the important features in making the model capable to simulate the surf zone conditions is the inclusion of wave breaking, is briefly described in the following section.

\section{Wave breaking}

In MIKE21 BW wave breaking is treated by using the roller concept developed in Deigaard (1989) and Schäffer et al. (1993): A roller volume of the individual breaking waves are determined at each time step as the volume of water above a line with a given slope. The slope is defined from a separate model that incorporates the onset of breaking and a gradual decay and termination of the roller separation line. The velocity of the roller volume is set equal to the local wave migration velocity whereby a set of roller momentum terms emerge in the momentum equations. For more detail see Madsen et al. (1997). 

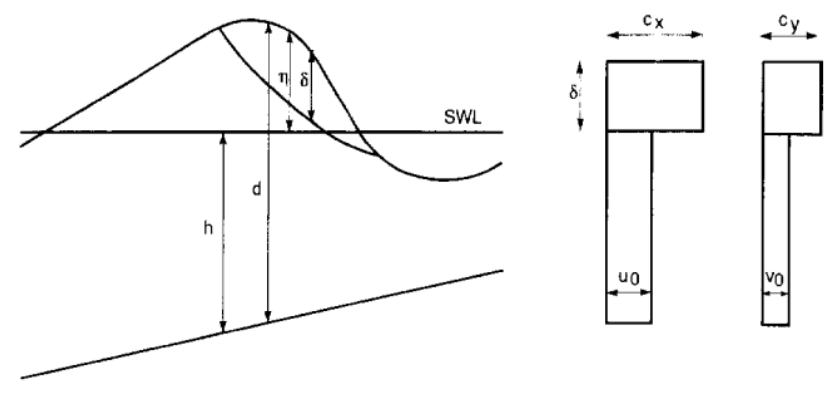

Figure 1. Roller concept for inclusion of wave breaking (from Schäffer et al. (1993))

In the roller model the angle of onset and the angle of taking out the roller are calibration parameters. In the present study the default values of $20^{\circ}$ and $10^{\circ}$ were used.

\section{Dune erosion and sediment transport}

In order to simulate the evolution of dunes during erosion, two mechanisms are of importance, namely the process of erosion caused by waves impinging the steep dune front, and sediment transport to redistribute the eroded material deposited in front of the dune.

The effect of erosion of steep fronts in the bathymetry was included developing a model that takes inspiration from a simple empirical relationship taking dune erosion volumes to be proportional to the impact force from waves impinging on the front (See Fisher et al. (1986), Overton et al. (1987), Nishi and Kraus (1996) and Larson et al. (2004)), i.e.

$$
E=K \cdot F_{\text {impact }}
$$

In order to translate this relation for the integrated properties into the present model with a spatial and temporal resolution, different strategies could be suggested. The following approach was developed and implemented in the model.

For each point on the steep slope the impact force and the corresponding erosion (and hence deposition) was calculated by applying a control volume as depicted in Figure 2 at each time step. This impact force is transformed to an erosion rate according to the above stated relation.

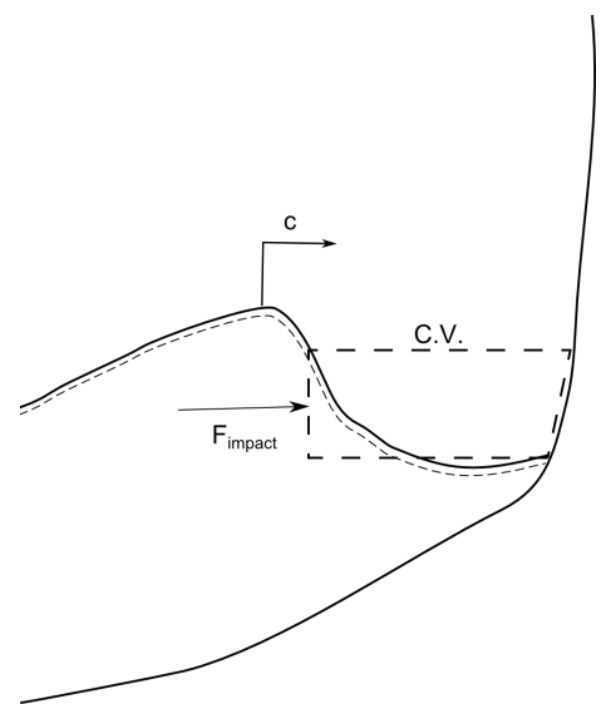

Figure 2. Wave impact and erosion 
The implementation of the changes in the bathymetry due to erosion of material may be thought of as an attempt to lump 1) local dune erosion of the lower part of the profile (dune foot notching) and 2) the failure of the dune part above as sketched in Figure 3 (see e.g. Erikson et al. (2007)): Based on the calculated erosion rate for the discrete sections the upper point of the given section is moved downwards according to the calculated material loss. Deposition of the total eroded material is introduced to the lowest cell.

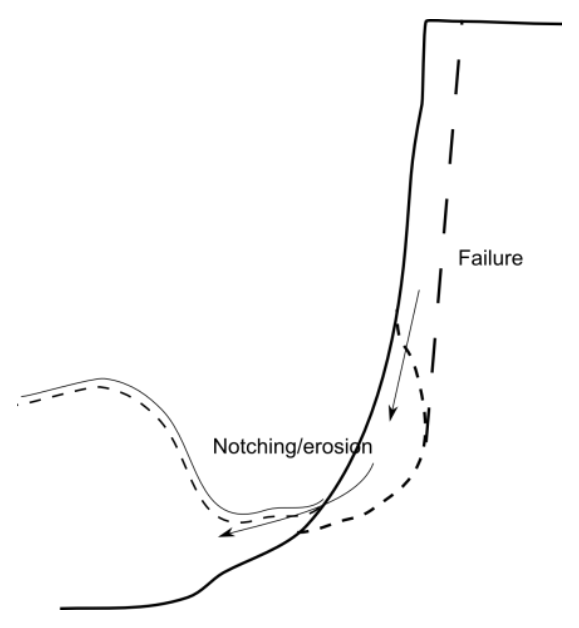

Figure 3. Dune erosion subprocesses: Erosion, notching and failure

Different model for of sediment transport were considered to represent the shear stress driven transport. This includes transport models ranging from detailed boundary layer model including the reproduction of time lag between wave boundary layer and outer layer flow and effects of roller turbulence penetrating the water column (such as MIKE21 STP based on the methodologies described e.g. in Fredsøe and Deigaard (1992)) to more simple parametric models. Initial tests revealed that the more simple sediment transport models would produce the right behavior for the profile evolution in front of the eroding dune. Being a test study for a new modeling concept, this was found to be sufficient to start with. Hence it was decided to include sediment transport by adopting a energetics formulation in its simplest form without acceleration correction terms (Bagnold (1966), based on the idea that the total load is connected to the local (near bed) dissipation - leading to a transport formula with a sum of two components: Bed load, where the velocity is taken to the power of 3 and suspended load where the velocity is taken to the power of 4). During the initial test phase it was furthermore noted that the resulting morphology was relatively insensitive to the power as long as the transport was scaled right to the right order of magnitude. The simulations shown in the present study is using a transport to the power of 3 and a scaling coefficient to match the order of magnitude expected.

The morphological change of the bed level $z$ was calculated applying the Exner equation

$$
\frac{\partial z}{\partial t}=-\frac{1}{1-n}\left(\nabla \cdot q_{s}+e-d\right)
$$

where $e$ and $d$ stand for erosion and deposition as dictated by to the dune erosion model described above. The total sediment load is $q_{s}$ and $n$ represents the porosity of the bed.

\section{Model tests}

Three tests of the above presented model were performed. 1) A test comparing the model with large scale dune erosion experiments (Deltaflume), 2) a test for the sensitivity to erosion and sediment transport rates and 3) a test of the effect of dune foot nourishment. 


\section{MODEL TEST 1: DELTAFLUME EXPERIMENTS}

\section{Deltaflume dune erosion}

The Deltaflume dune erosion experiments (van Gent et al. (2008), van Thiel de Vries et al. (2008)) were used to study and validate the model's behavior. The model results presented here are for test T01 only. Initial model runs for T02 and T03 were made showed that the overall behavior of the model (as well as the experiments) will follow the pattern seen for the case of T01- a more thorough presentation including all the experiments is expected to be given in the future, also including simulations of the double dune profiles D01 and D02.

\section{Flow results}

The model was run for 6 hours driven by a random wave series with the same statistics as reported for T01 in van Thiel de Vries et al. (2008). The model was run with standard roller settings. The model results were analyzed in terms of wave heights along the profile, including total wave height, wave heights for low frequency motion and wave heights for high frequency motion. The result of this analysis is shown in Figure 4 where the overall wave height distribution over the profile is seen. This figure shows that the trends and order of magnitude, both regarding the overall energy dissipation and also the evolution of low and high frequency energy parts, are reproduced fairly well in the model. Some discrepancy is noted for the high frequency waves for $\mathrm{x}<150 \mathrm{~m}$. Also a minor deviation between model and data for the decay of high harmonics waves close to the dune is observed. For the case of dune erosion, modeling the combined effect of low and high frequency motion is believed to be important (as also discussed in Roelvink et al. (2009)), and as a test the result is found to be satisfactory.

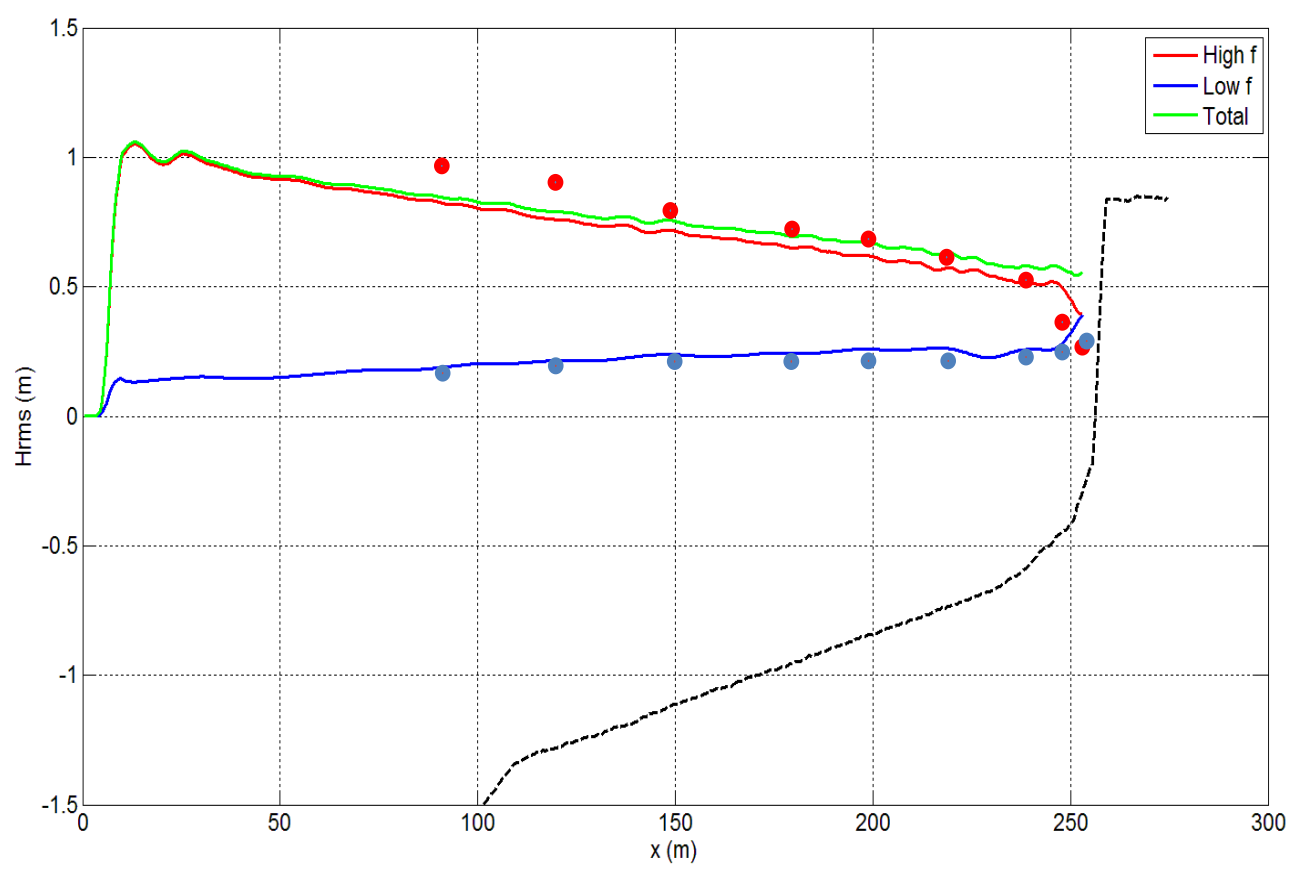

Figure 4. Spatial evolution of root mean square wave height along profile. Green curve: The total wave height. Red curve: High frequency motion wave height. Blue curve: Low frequency motion wave height. Dots indicate T01 measurements - taken from van Thiel de Vries et al. (2008).

\section{Temporal evolution}

It is noted by van Thiel de Vries et al. (2008) that the wave height in the experiments tended to have higher waves in the beginning of the experiment than after 2 hours (here after the wave height seems to be more or less constant even though only two points in time are presented). The study indicates that this temporal evolution is a function of the profile shape and not an effect a drift in the forcing during the experiment. 
This behaviour is however not well represented in the model, as the wave heights had a tendency to be more constant in time over the simulated period (after an initial warm up period with lower waves, the wave height change is much smaller than in the experiment). One reason for this may be due to the modelling of wave breaking, which may overestimate the breaking in the beginning of the simulation and as the profile evolves underestimates the importance of the profile on the wave breaking.

The problem of modelling the gradual temporal evolution of the overall flow patterns along the profile (mean current, wave height and period) as function of the evolution of the profile shape an interesting feature, and is important to capture for accurate morphological modelling - also in the case of dune erosion - and will be followed up in the future. Despite this discrepancy we can also note that the overall features are definitely present in the model, and that the order of magnitude of both short and long waves is correct (without much calibration). The overall behaviour of the modelled morphology is hence expected to be in the right order of magnitude if the effects of erosion and sediment transport are represented well.

\section{Morphological results}

Figure 5 shows the result of running the morphological model 6 hours with two choices of calibration settings plotted together with the results from the experiments. Calibration was done on the sediment transport capacity coefficient and the erosion rate scaling coefficient only, i.e. not on the flow parameters. Model calibration (a) corresponds to using the final volume after 6 hour as calibration target. Model calibration (b) corresponds to calibration of the model against the early stages of the evolution ( $<2$ hour). Model (b) was found to have a transport rate of a factor 2 compared to model (a).

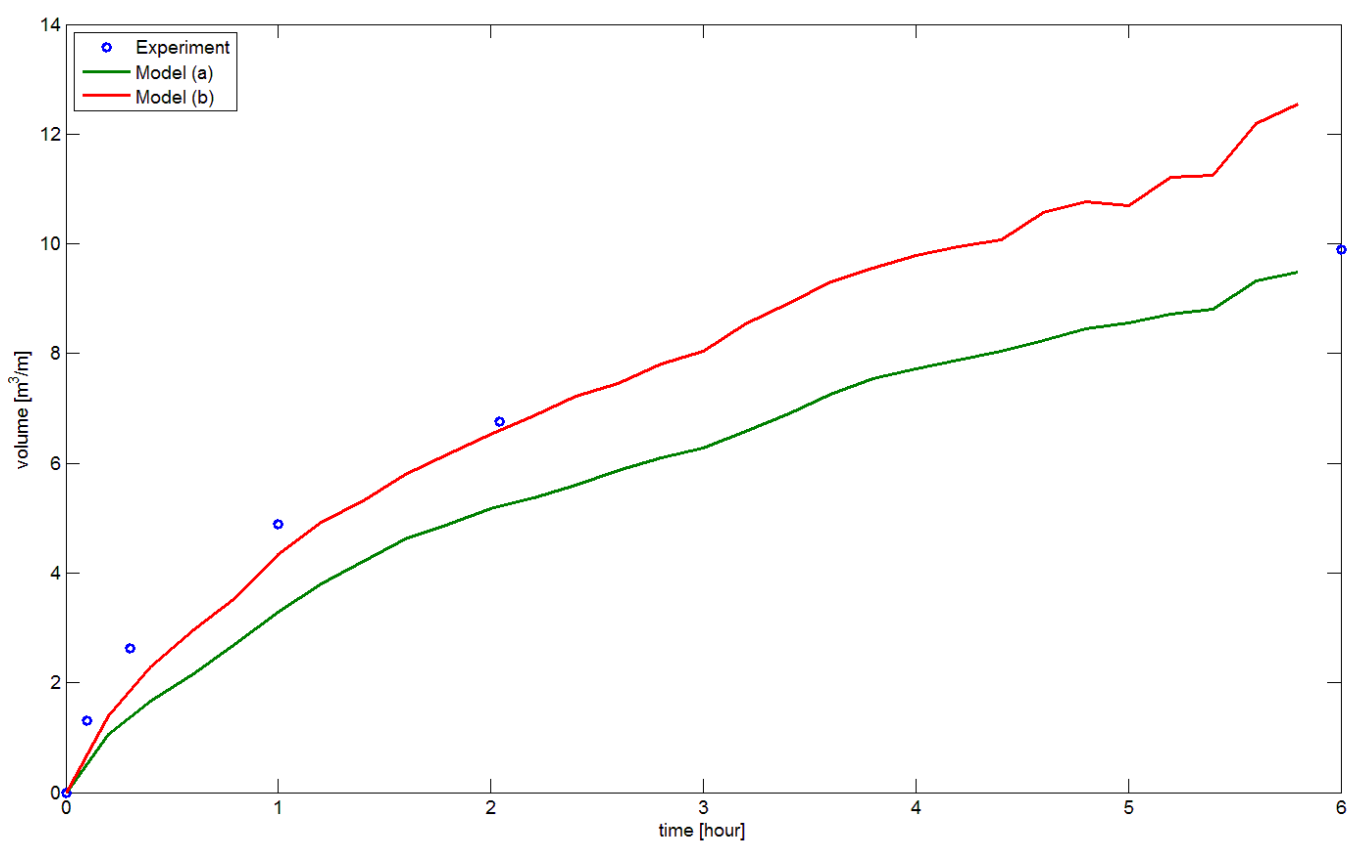

Figure 5. Temporal development of volume displacement. Experiment T01 versus model results.

The overall feature of the curves is that the speed of the temporal evolution generally is faster in the beginning of the run and gradually reduces over time as the profile evolves. The difference in the evolution speed for different sediment transport rates (a) and (b) is interesting, because it resembles an approximate test of the importance of the temporal discrepancy between mean flow characteristics in the model and in the laboratory test (discussed under the flow section above). In the measurements van Thiel de Vries et al. (2008)) found that the sediment concentration would be up to $80 \%$ higher in the beginning of the experiments compared to after 2 hours. Comparing to the evolution of the two model settings (a) and (b) hence reveals that the erosion and redistribution seems to capture the right behaviour of the morphology given the right hydrodynamic forcing. If the wave height would have been higher in the beginning of the simulation, the curve for the simulated volume displacement would most likely have reproduced the here mentioned temporal details in the laboratory data set even better. Even 
though the simulated evolution has a reasonable order of magnitude and overall evolution rates for both model (a) and (b), the present test indicates that the model could be improved by further improving the flow models response to the profile bathymetry.

In Figure 6 the resulting modeled morphology is shown in the case of model (a) after 6 hours plotted together with the experimental data and the initial bathymetry. It is noted that the shape of the modeled profile result is in good agreement with the laboratory test except for minor variations in the offshore migrating front (weak 'bar-like' undulations and a more gradual transition to the deeper parts). The model is seen to be able to produce the correct shape of the upper part of the profile, i.e. the eroding dune, and that the model is capable of taking the eroded sediment out through the profile. The result is promising for the future use of the model as is indicates that the present concept most probably includes the right mechanisms and that the implementation gives robust results.

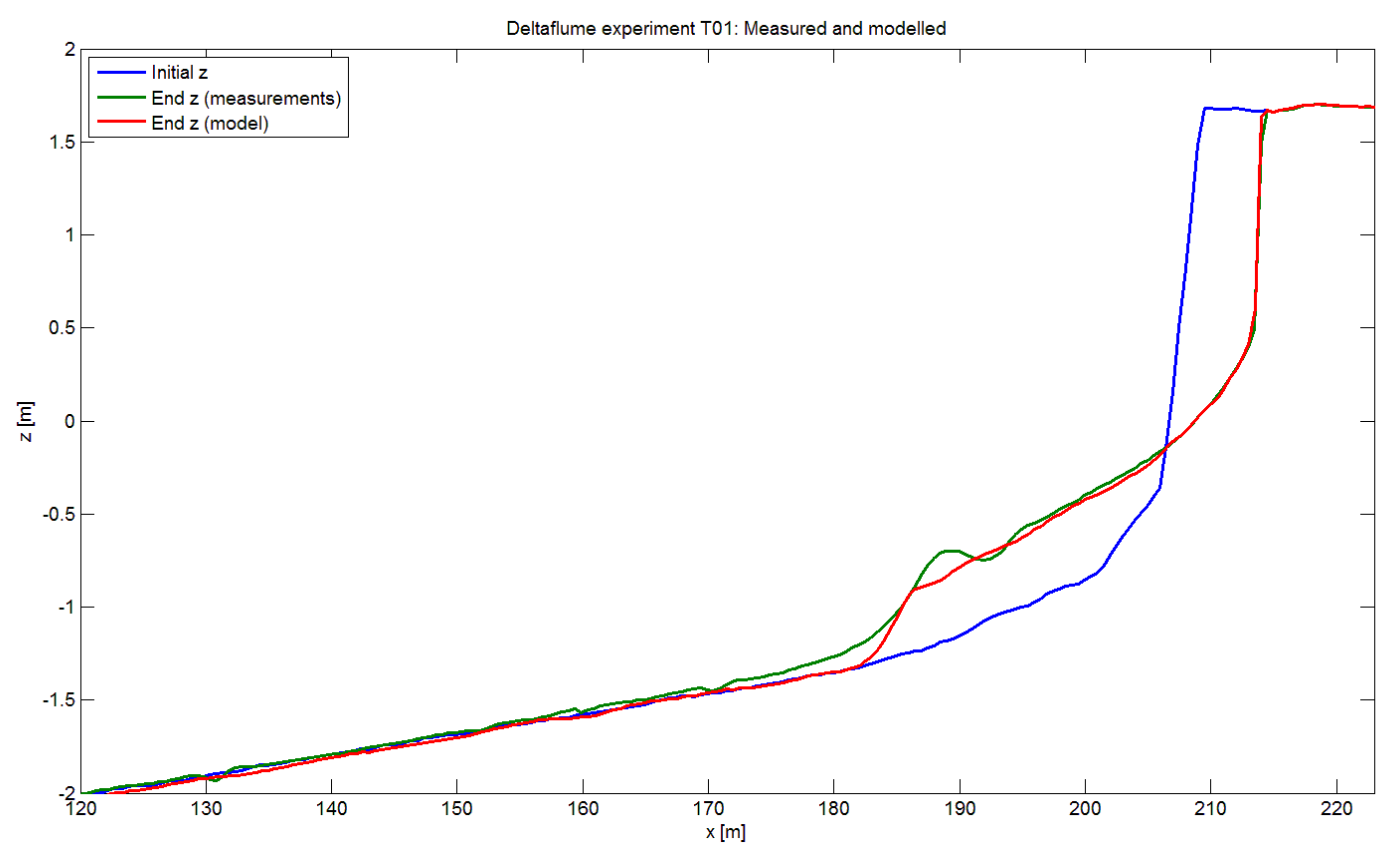

Figure 6. Example of model results versus experimental data - T01, after 6 hours.

\section{MODEL TEST 2: SENSITIVITY TO EROSION PARAMETERS}

In order to test the model behavior, the model was run for different variations of the erosion and sediment transport rates. In the following we present the resulting profiles for the test, one profile for the 'reference run' and two for a smaller and higher value of the given parameter respectively.

\section{Erosion rate}

In Figure 7 the resulting profiles for the case of varied erosion rates are presented. A reference run (red curve) was run made and run again with the same set up except for changes of the erosion rate by a factor 1.5 (blue) higher and 0.5 (green) lower. The figure clearly shows that the retreat of the dune front accelerates for increasing erosion rate value, but also that it has different consequences for the profile. The higher erosion rate, the higher the dune foot tends to be, and the further off-shore the submerged part of the profile has migrated. The submerged part of the profile is seen to end up with higher z-levels for a higher erosion rate. The slope of the profile just off the dune foot/front is seen to steepen somewhat for decreasing the erosion rates. The observed effects are however seen to be small for the perturbations chosen. This may indicate in more general terms that the morphological evolution is relatively insensitive to this the exact value of the erosion rate, which will be an interesting feature because the erosion rate must be given as an empirical parameter and hence have a large degree of uncertainty (and in nature complications such as vegetation and soil moisture content adds to this uncertainty). 


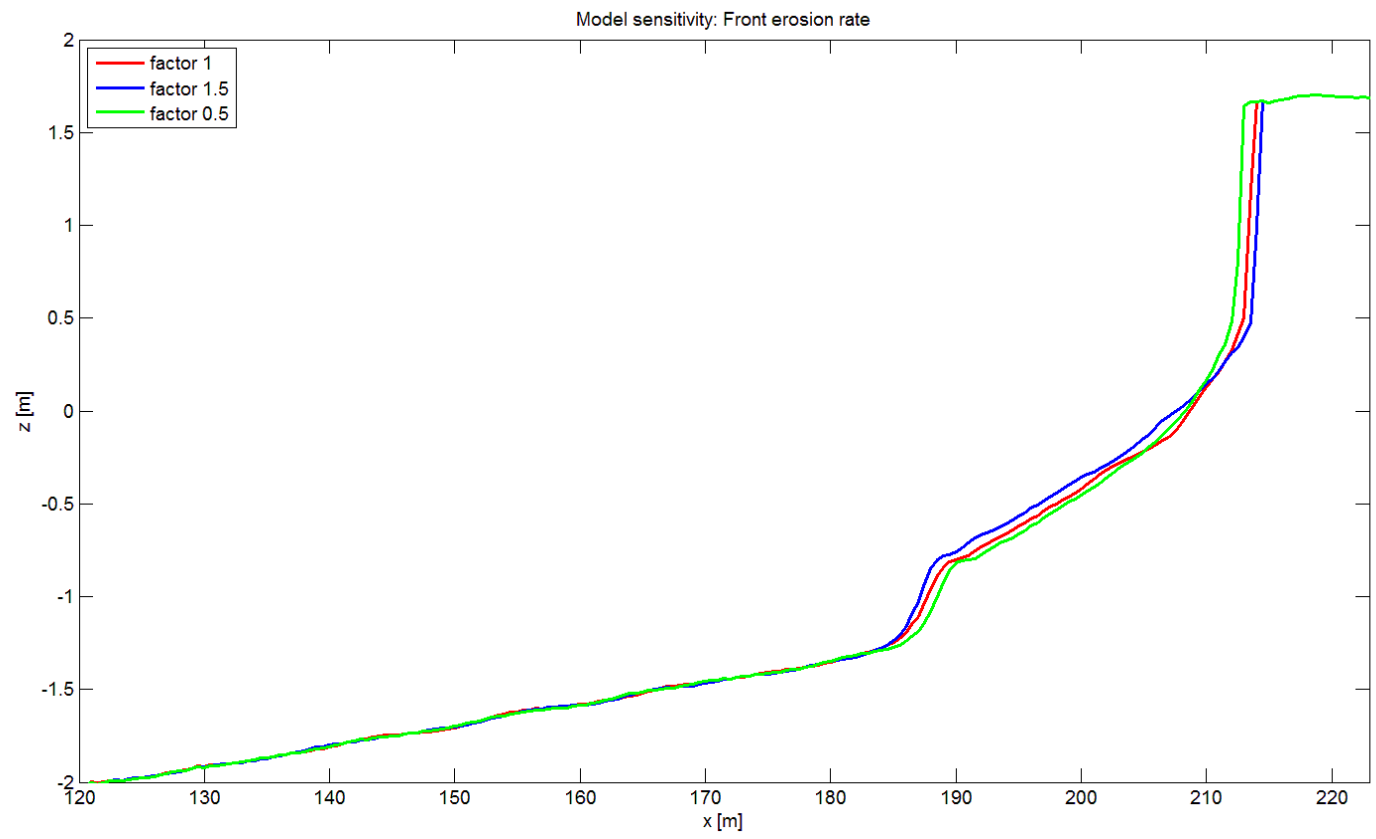

Figure 7. Sensitivity test for erosion rate. Profile after 6 hours run.

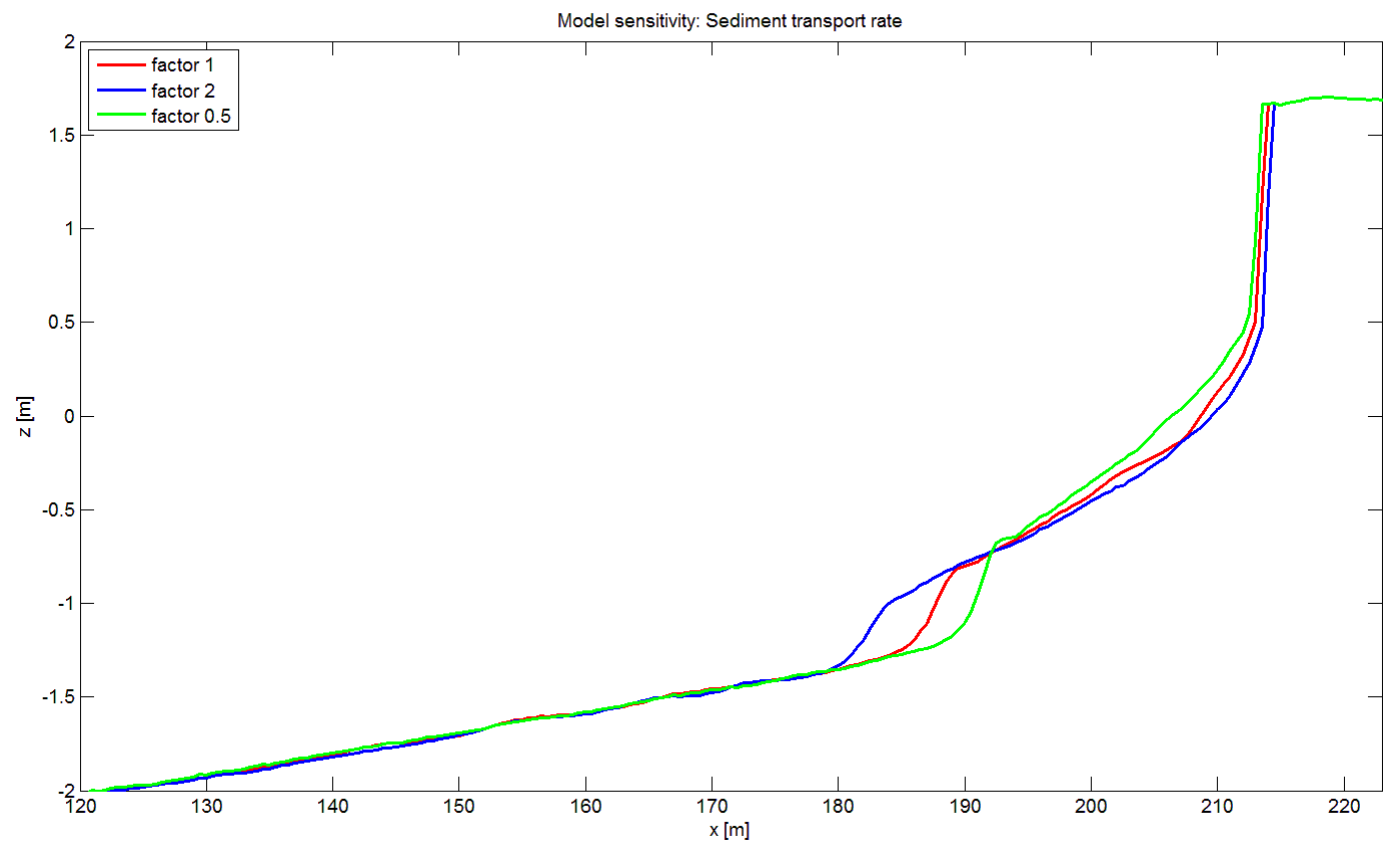

Figure 8. Sensitivity test for sediment transport rate. Profile after 6 hours run.

\section{Sediment transport}

The same type of exercise as for the erosion rate was made for the sediment transport. Here the reference run was varied by a factor 2 and 0.5 on the rate of transport. The result of running the models is shown in Figure 8 for the profiles after 6 hours. Not surprising the effect is seen most pronounced at the outer part of the profile where the larger transport rates takes the sediment farther off-shore, but as in the case of the erosion rate tests, there are effect on the entire profile including the dune and the degree of dune front retreat. Generally the effect of the sediment transport is that sediment is taken from the inner part of the profile and deposited at the outer part. This means that for a given supply of sediment from dune erosion, the dune foot position would lower if the magnitude of the transport rates 
increases. The slope of the upper part of the profile also changes. In general the overall effect is that the dune front become more exposed such that waves can reach the dune front more unhindered when the transport rate is increased.

One conclusion of this exercise is that sediment transport model is important for the overall behaviour of the system, and that improvements of the description of this part will improve the overall prediction capacity of the model.

\section{MODEL TEST 3: DUNE FOOT NOURISHMENT}

The model was run for a set of numerical tests where a pile of sand was introduced at the dune foot, with a linear profile as shown in Figure 9. The nourishment configurations where introduced so that three different heights of the upper part of nourishment profile where obtained namely at $\mathrm{z}=\{0 \mathrm{~m}$, $0.5 \mathrm{~m}, 1 \mathrm{~m}\}$, and with six different slopes $1: \mathrm{S}, \mathrm{S}=\{5,6,7,8,9,10\}$.

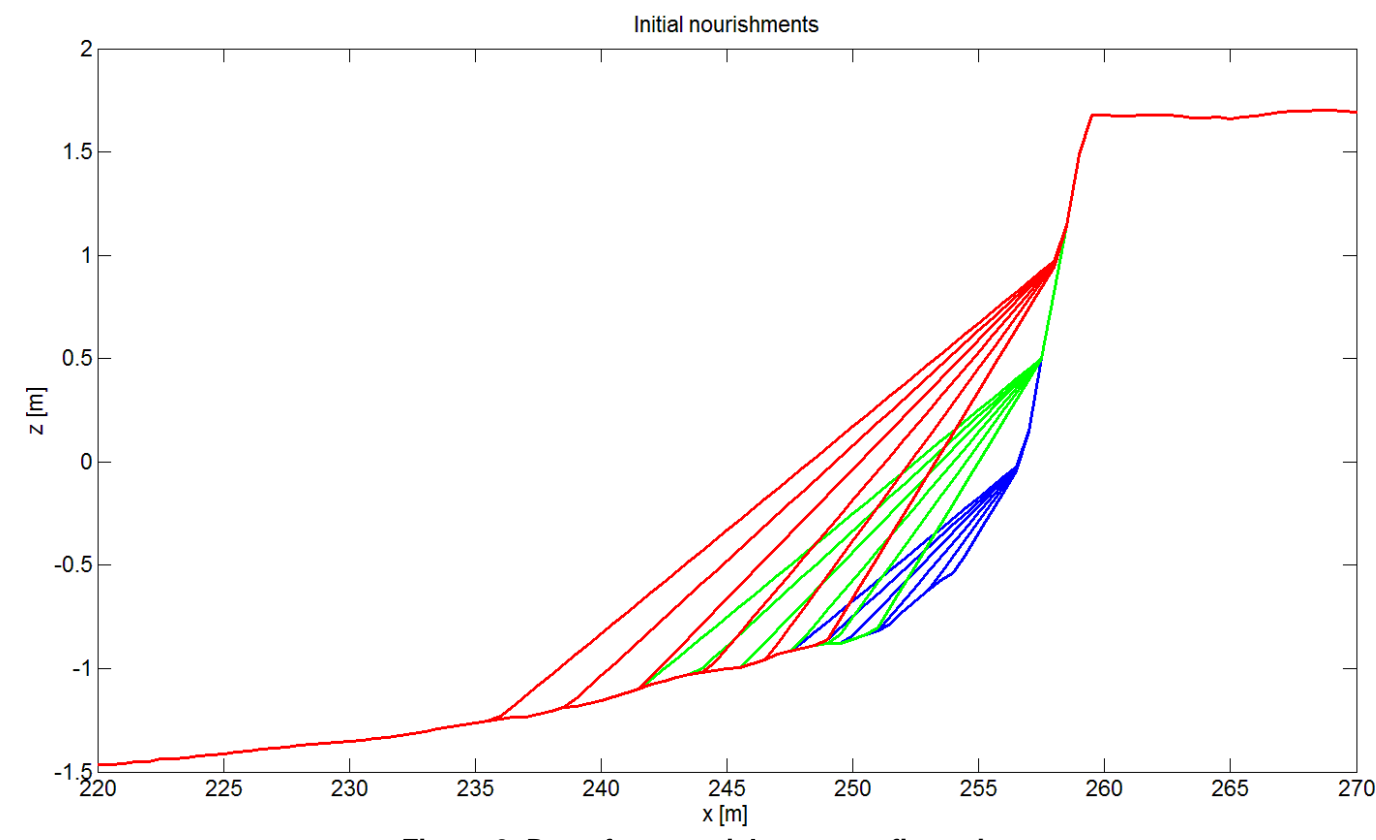

Figure 9. Dune foot nourishment configurations

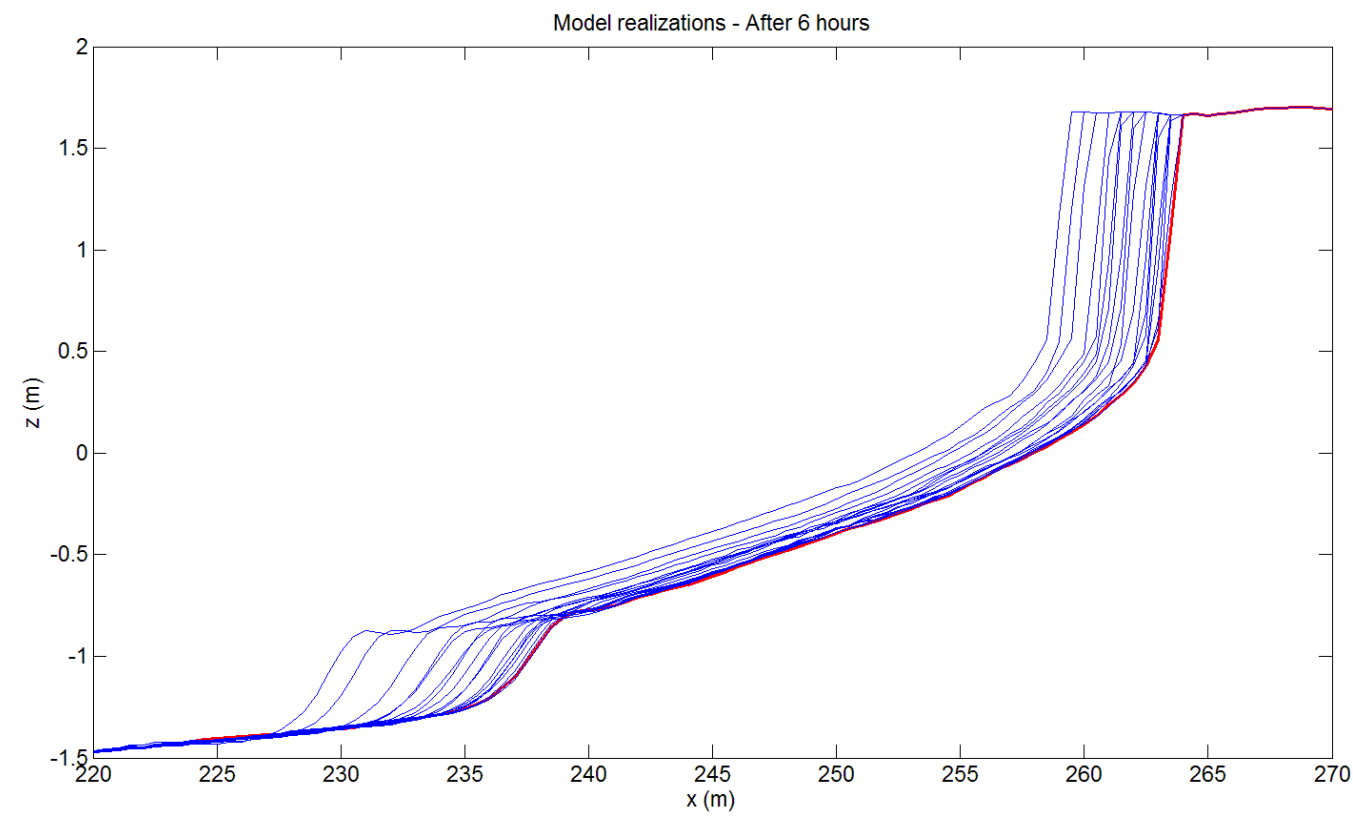

Figure 10. Model results from the nourishment test runs. 
The model was again run for 6 hours and a set of different realizations were obtained as depicted in Figure 10. As observed in the figure, the nourishment yield different responses with respect to the dune front retreat. It is also noted that there is a large degree of similarity between the profiles, indicating that the effect of the nourishment is 'smoothed out' over the entire profile.

In Figure 11 the correlation between the relative slow down of the dune front retreat as function of the nourishment volume is shown (the 'nourishment efficiency' $\Delta \mathrm{x}$ being the distance from the dune front without nourishment to the dune front for a given nourishment configuration). The figure reveals as expected a clear correlation between the slow down of dune front retreat and the volume of sand added to the profile. It is noted that the relationship is almost linear as expected when the profile shape are very similar in shape $(\Delta \mathrm{x}=\Delta \mathrm{Vol} /($ active height $))$. A small deviation from the linear relation is also seen. This corresponds to the volumes deposited in the very outer part of the profile. Here the deposition of material corresponds more or less to an increase in morphological active height.

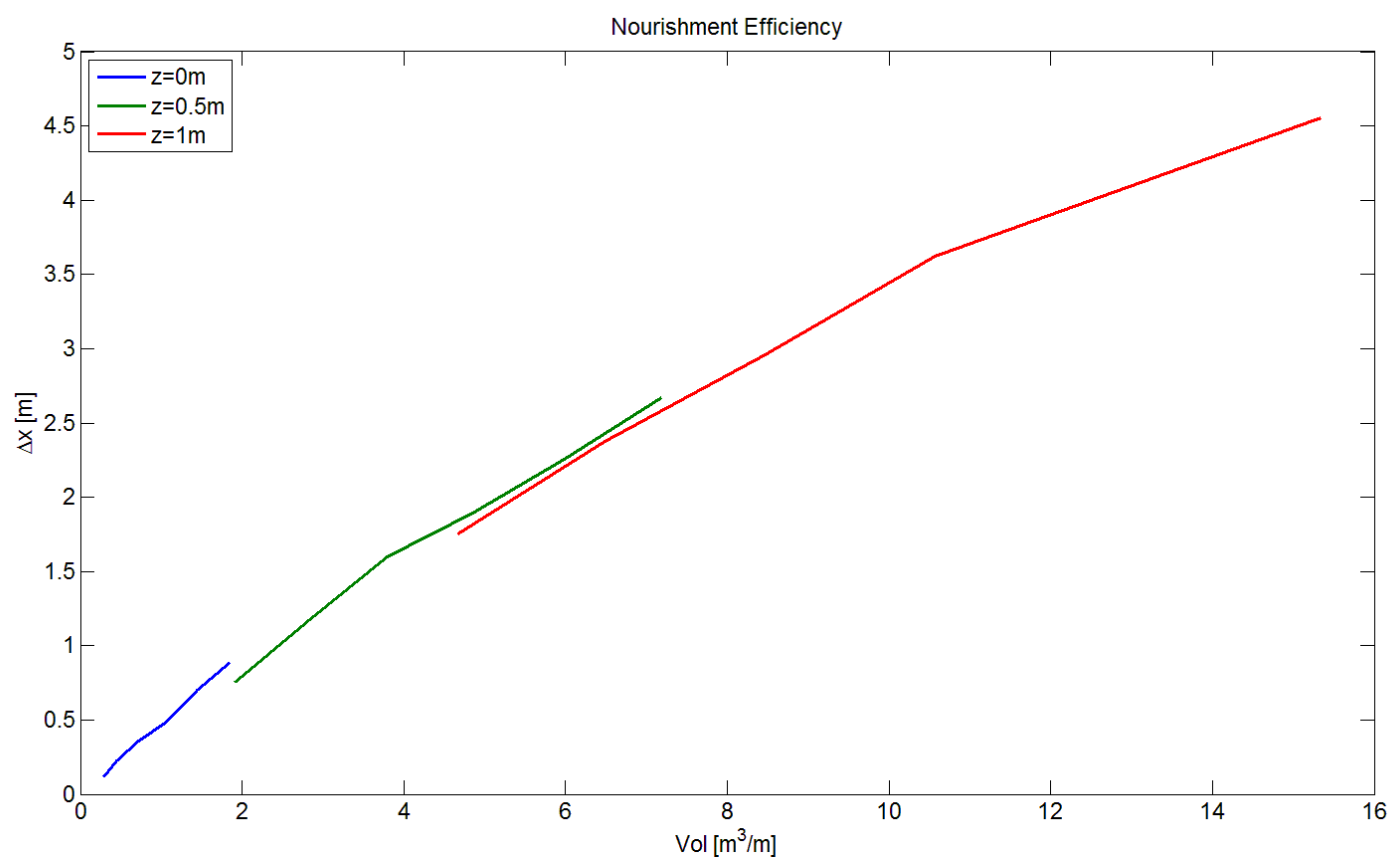

Figure 11. Nourishment efficiency after 6 hours. $\Delta x$ defined as the position of the dune front relative to the dune front position without nourishment.

The main conclusion from the nourishment tests is that the model produces the expected behavior namely that the profiles all reshapes within the time limit of 6 hours independently of the initial profile (for a given set of wave conditions), and that only slight variations occur due to detailed geometry at the migrating (submerged) front.

\section{CONCLUSIONS}

A model for dune erosion based on the Boussinesq wave model M21BW (in-house developer version) has been presented. The effects of dune front erosion, material slumping and sediment transport has been implemented in the existing wave model and tests have been made against one of the Deltaflume experiments (T01). The results encourage further development of the method in future. The simulations showed that the coupling between the flow and the evolving bed gives plausible results. A sensitivity test for the erosion and sediment transport rates illustrated how the dune front erosion and evolution of the submerged part of the profile interacts. The model was also capable of producing the regeneration of the profile for a variety of different initial dune foot nourishment profiles, and produced an expected correlation between dune front retreat and volume added. Many key features have been identified for further development, such as a more deterministic sediment transport formulation and a further development of the wave model e.g. improving further the behavior of the wave roller model for wave breaking.

More test and model runs are on the way and expected to be presented in the future where the most important will be: 1) Further development of the comparisons with large scale dune erosion tests. 2) 2DH calculations. 3) Application of the dune erosion model to cases with dune breaching. 


\section{ACKNOWLEDGMENTS}

This work was partly developed under the project: Danish Coasts and Climate Adaptation - flooding risk and coastal protection (COADAPT), financed by the Danish Council for Strategic Research (DFS), project no 09-066869.

\section{REFERENCES}

Bagnold, R.A., 1966, An approach to the sediment transport problem from general physics. Prof. Paper, 422-1, U.S.G.S.

Deigaard, R., 1989, Mathematical modelling of waves in the surf zone, Progress Report No. 69, Inst. Hydrodynamics and Hydraulic Eng. (ISVA), Technical Univ. Denmark, pp. 4759.

Drønen and Deigaard, 2011, A Model for Wave Induced Erosion of Sandy Barriers, Proceedings in RCEM, River, Coastal and Estuarine Morpholdynamics, Beijing, China.

Dette, H.H, Larson, M., Murphy, J., Newe J., Peters, K., Reniers, A., Steetzel, H., 2002, Application of prototype flume tests for beach nourishment assessment, Coastal Engineering, 47, pp. 137-177.

Erikson, L.H., Larson, M., Hanson, H., 2007, Laboratory investigations of beach scarp and dune recission due to notching and subsequent failure, Marine Geology, 245, pp. 1-19.

Fisher, J.S., Overton, M.F., Chisholm, T, 1986, Field measurements of dune erosion. Proceedings of the $20^{\text {th }}$ Coastal Engineering Conference, ASCE, pp. 1107-1115.

Fredsøe, J, Deigaard, R, 1992, Mechanics of Coastal Sediment Transport, Advanced Series on Ocean Engineering - Volume 3, World Scientific, Singapore, 369pp.

Fuhrman, D.R., Madsen, P.A., 2008, Simulation of nonlinear wave run-up with a high order Boussinesq model, Coastal Engineering, 55, pp. 139-154.

Hubbard, M., Dodd, N., 2002, A 2D numerical model for wave run-up and overtopping, Coastal Engineering, 47, pp. 1-26.

Hughes, S.A., Nadal N.C., 2009, Laboratory study of combined wave overtopping and storm surge overflow of levee, Coastal Engineering, 56, pp. 244-259.

Kobayashi, N., Farhadzadeh, A., Melby, J., Johnson, B., Gravens, M., 2010, Wave overtopping of Levees and Overwash of Dunes, Journal of Coastal Research, 26, 5, pp. 888-900

Lynnet, P.J., Melby J.A., Kim, D., 2010, An application of Boussinsq modeling of Hurricane wave overtopping and inundation, Ocean Engineering, 37, pp- 135-153.

Madsen, P.A., Sørensen, O.R., Schäffer, H.A., 1997, Surf zone dynamics simulated by a Boussinesq type model, Part I: Model description and cross-shore motion of regular waves, Coastal Engineering, 33, pp. 155-176.

MIKE21 STP, 2012, MIKE21 Sediment Transport Model, Scientific Documentation, DHI, Denmark.

Nishi, R., Kraus, N.C., 1996, Mechanism and calculation of sand dune erosion by storms. Proceedings of the $25^{\text {th }}$ Coastal Engineering Conference, ASCE, pp. 2325-2339.

Overton, M.F., Fisher, J.S., 1988, Laboratory investigation of dune erosion. Journal of Waterway, Port, Coastal and Ocean Engineering 114 (3), pp. 367-373.

Pontillo, M., Schmocker, L., Hager, W.H., 2010, 1D numerical evaluation of dike erosion due to overtopping, Journal of Hydraulic Research, Vol. 48, pp. 573-582.

Roelvink D., Reniers A., van Dongeren A., de Vries J.T., McCall R., Lescinski J., 2009, Modeling impact on beaches, dunes and barrier islands, Coastal Engineering, 53, pp. 1133-1152.

Schäffer, H.A., Madsen, P.A. and Deigaard, R., 1993, A Boussinesq model for waves breaking in shallow water, Coastal Engineering, Vol. 20 (3-4), pp. 185-202.

Tuan, T.Q., Oumeraci, H., 2010, A numerical model of wave overtopping on seadikes, Coastal Engineering, 57, pp. 757-772.

van Gent, M.R.A., van Thiel de Vries, J.S.M., Coeveld, E.M., de Vroeg, J.H., van de Graaf, J., 2008, Large Scale dune erosion tests to study the influence of wave groups, Coastal Engineering, 55, pp. 1041-1051. 